\title{
Valentyn Serheyev
}

\section{ENTHALPIES OF MIXING METHYLMETHACRYLATE WITH SOME ORGANIC SOLVENTS}

\author{
Lviv Polytechnic National University \\ 12 Bandery str., 790013 Lviv, Ukraine \\ vsergeev@polynet.Iviv.ua
}

Received: October 30, 2011/ Revised: December 09, 2011 / Accepted: December 19, 2011

(C) Serheyev V., 2012

\begin{abstract}
Using a calorimetric method enthalpies of mixing of the binary systems of methylmethacrylate with acetonitryle, hexane, benzene, 1,2-diclorethane, and acetic acid at $293 \mathrm{~K}$ and atmospheric pressure have been measured. The concentration dependences of enthalpies of mixing were correlated by polynomials.
\end{abstract}

Keywords: solutions, calorimetric methods, enthalpies of mixing, methylmethacrylate, acetonitryle, hexane, benzene, 1,2-diclorethane, acetic acid.

\section{Introduction}

Mixing of different compounds results in solutions whose properties are not ideal. Deviation from ideality is expressed by many thermodynamic variables, particularly by excess properties. Excess thermodynamic properties of mixtures correspond to the difference between the properties of actual and ideal systems, and thus are useful in the study of molecular interactions and arrangements. In particular, they reflect the interactions that take place between solute-solute, solute-solvent, and solvent-solvent species. For example, negative value of enthalpy of mixing indicates that molecular interactions in solution are stronger than those of individual components.

This work is part of our study of characteristics of molecular interactions between solvents and commercially important monomers, in particular, the influence of the chemical structure of the solute in the systems under consideration. Methacrylic esters and hexane, benzene, 1,2-diclorethane and acetic acid are important industrial chemicals used in the large-scale preparation of useful polymers. The esters are also interesting because they contain both a double bond and an ester group.

The properties of solutions of esters of acrylic row acids were described by many authors in the published works. J. George et al. [1] defined the heat of mixing and excess volumes of methylmethacrylate solutions with benzene, toluene, $p$-xylene, cyclohexane, and aliphatic diethers. In the works of R. Peralta and others [2-6] excess volumes of solutions of methylmethacrylate, ethyl- and butyl-acrylate in styrene, $m$-xylene, benzene and 1,4-dioxane was established. J. Wisniak et al. [7, 8] established density and excess volumes for esters of methacrylic acid in aliphatic ethers and toluene. In the works of N. Sastry $[9,10]$ excess volumes and viscosity for esters of acrylic and methacrylic acids were established.

From all known methods of determination of thermal effects calorimetric method is considered as one of the most reliable [11, 12].

At the same time, there are no publications devoted to direct calorimetry determination of the enthalpies of mixing of methylmethacrylate (MMA) with acetonitryle, 1,2-diclorethane, and acetic acid.

\section{Experimental}

\subsection{M aterials}

The raw materials used for enthalpies of mixing measuring were supplied by MERCK (Germany). The chemicals received were further purified through repeated evaporation and benzene and acetic acid - additionally by recrystallization. The chemicals were then selected based on their unique densities and refractive index. The contamination was kept below 0.2 wt $\%$, as verified through chromatography. The densities of the purified reagents at $293 \mathrm{~K}$ were determined and their values are reported in Table 1 along with the values given in the literature. 
Purity, density and refractive index of pure components at $293 \mathrm{~K}$

\begin{tabular}{|l|c|c|c|c|c|}
\hline \multirow{2}{*}{ Component } & \multicolumn{2}{c|}{$n_{D}{ }^{20}$} & \multicolumn{2}{c|}{$\rho, \mathrm{g} / \mathrm{cm}^{3}$} & \multirow{2}{*}{$\begin{array}{c}\text { Purity, } \\
\text { mass \% }\end{array}$} \\
\cline { 2 - 5 } & literature & measured & literature & measured & \\
\hline Acetonitryle & $1.3437[13]$ & 1.3441 & $0.7822[13]$ & 0.7821 & 99.8 \\
\hline Benzene & $1.5011[13]$ & 1.5009 & $0.8790[13]$ & 0.8787 & 99.9 \\
\hline Hexane & $1.3750[13]$ & 1.3751 & $0.6594[13]$ & 0.6593 & 99.9 \\
\hline 1,2-Diclorethane & $1.4448[14]$ & 1.4445 & $1.2530[14]$ & 1.2533 & 99.8 \\
\hline Acetic acid & $1.3717[13]$ & 1.3716 & $1.0491[13]$ & 1.0491 & 99.9 \\
\hline Methylmethacrylate & $1.4146[14]$ & 1.4145 & $0.9432[14]$ & 0.9434 & 99.8 \\
\hline
\end{tabular}

\subsection{Enthalpies of Mixing M easurements}

The enthalpies of mixing were measured by differential microcalorimeter MID-200 with the use of ampoules methodology. The mixing chamber and the pin were made of glass and the sealing gasket was made of teflon. The volume of the mixing chamber was $15.870 \mathrm{~cm}^{3}$. The first component of mixture poured directly into the chamber and the second was soldered in a glass ampoule. The chamber and the ampoule were weighed before and after filling to within $5 \cdot 10^{-5} \mathrm{~g}$. Then the filled chamber with the ampoule was loaded in the microcalorimeter and thermostated to within $0.1 \mathrm{~K}$ at the temperature of $293 \mathrm{~K}$. After establishment of thermal equilibrium in the system the ampoule was broken by the glass pin. The power of thermal stream between the chambers of the microcalorimeter was fixed by a voltmeter to within $1 \mu \mathrm{V}$, which corresponded to $8 \cdot 10^{-6} \mathrm{Wt}$. After every experiment the calorimeter was calibrated by the internal calibration system.

To minimize the heat which is emitted as a result of partial condensation of the component which is directly in the chamber and the heat which is absorbed at evaporation of the component from the broken ampoule, the component with lower vapour pressure was poured into the ampoule.

For verification of reliability of the presented methodology a series of experiments on determination of enthalpies of mixing of equimolar solution benzenehexane conducted. The obtained value of $884.3 \pm 3.4 \mathrm{~J} / \mathrm{mol}$ does not differ from the published in [12] values $883.4 \pm$ $\pm 1.5 \mathrm{~J} / \mathrm{mol}$ more than by the experimental error.

\section{Results and Discussion}

The enthalpies of mixing for solutions $\Delta_{m i x} H_{293}$, the heat emitted during the experiment $Q$, the masses of ester $m_{e}$, masses of solvent $m_{s}$ and mole fraction $N_{s}$ of the first component of solution are reported in Table 2 .

The enthalpies of mixing for the investigated solutions were correlated using the polynomials [8]:

$$
\Delta_{m i x} H_{293}=a_{0}+a_{1} x+a_{2} x^{2}+a_{3} x^{3}+a_{4} x^{4}
$$

The standard deviation $S$ was calculated as

$S=\left[\Sigma\left(\Delta_{m i x} H_{293},{ }^{\exp }-\Delta_{m i x} H_{293},{ }^{\text {calc }}\right)^{2} /(N-1)\right]^{1 / 2}$

The coefficients of polynomials and the respective values of $S$ appear in Table 3 and are necessarily consistent. The value of standard dispersion is commensurable with the experimental error. Therefore the obtained polynomials can be used for the calculation of enthalpies of mixing of the investigated solutions of any concentration.

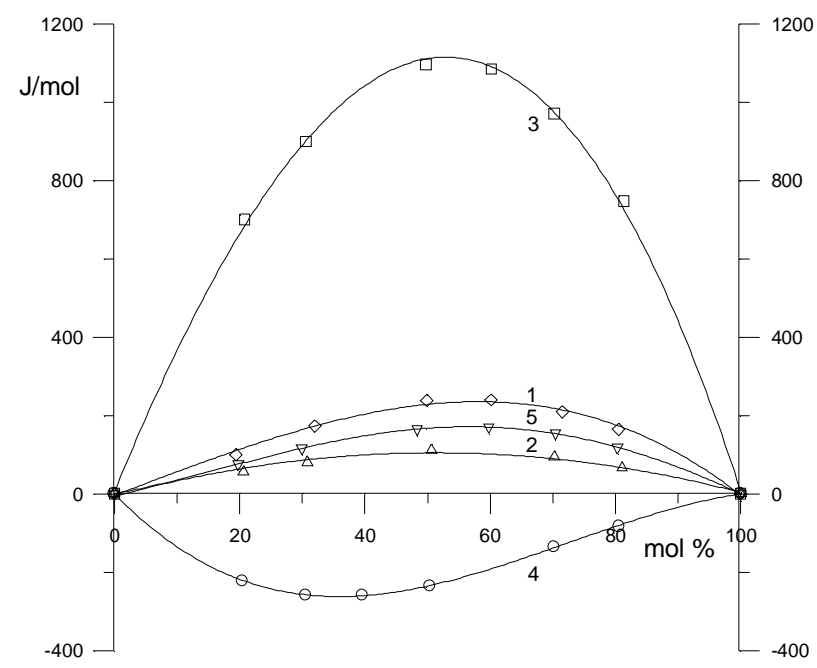

Fig. 1. Concentration dependences of enthalpies of mixing for the investigated system at $293 \mathrm{~K}$ : Acetonitryle-MMA (1); Benzene-MMA (2); Hexane-MMA (3); 1,2-Diclorethane-MMA (4) and MMA-Acetic acid (5)

Fig. 1 shows the dependences of enthalpies of mixing for the investigated solutions on the concentration of the first component of the system. For the systems Hexane-MMA and Benzene-MMA concentration dependence of enthalpies of mixing is a symmetric parabola with the maximum corresponding to equimolar composition. It is therefore possible to suppose that in the above systems association of molecules is either absent or corresponds to equimolar composition [2]. For the systems Acetonitryle-MMA and MMA-Acetic acid the 
maximum of the curve of concentration dependence of mixing heat corresponds to $60 \mathrm{~mol} \%$ of the solvent, and for the system 1,2-Diclorethane-MMA the maximum corresponds to $33 \mathrm{~mol} \%$. Concentrations of solutions corresponding to the maximums on the curves of concentration dependence of heat of mixing for the investigated systems indicate the possible associations of molecules in these systems.

Table 2

The enthalpies of mixing for investigated solutions at 293K

\begin{tabular}{|c|c|c|c|c|}
\hline$m_{e}, \mathrm{~g}$ & $m_{s}, \mathrm{~g}$ & $N_{s}, \mathrm{~mol} \%$ & $Q, \mathrm{~J}$ & $\Delta_{m i x} H_{293}, \mathrm{~J} / \mathrm{mol}$ \\
\hline \multicolumn{5}{|c|}{ Acetonitryle-MMA } \\
\hline 4.15630 & 0.41125 & 19.44 & 5.127 & 99.5 \\
\hline 3.37005 & 0.65005 & 31.99 & 8.585 & 173.5 \\
\hline 3.21915 & 1.31305 & 49.87 & 15.260 & 237.9 \\
\hline 1.87300 & 1.15910 & 60.15 & 11.242 & 239.5 \\
\hline 2.05840 & 2.11810 & 71.51 & 15.093 & 209.2 \\
\hline 1.83960 & 3.11360 & 80.50 & 15.516 & 164.7 \\
\hline \multicolumn{5}{|c|}{ Benzene-MMA } \\
\hline 4.72345 & 0.95610 & 20.48 & 3.356 & 56.5 \\
\hline 3.25295 & 1.12970 & 30.37 & 3.781 & 80.5 \\
\hline 2.88900 & 2.31060 & 49.99 & 6.496 & 111.2 \\
\hline 1.77145 & 3.26810 & 70.22 & 5.667 & 95.2 \\
\hline 1.12345 & 3.75630 & 79.949 & 3.895 & 65.7 \\
\hline \multicolumn{5}{|c|}{ Hexane-MMA } \\
\hline 4.53690 & 1.02380 & 20.77 & 40.014 & 699.6 \\
\hline 3.14390 & 1.19065 & 30.55 & 41.179 & 910.7 \\
\hline 2.89680 & 2.46690 & 49.73 & 63.104 & 1096.3 \\
\hline 1.68055 & 2.18360 & 60.15 & 45.372 & 1077.1 \\
\hline 1.26575 & 2.57325 & 70.25 & 41.239 & 970.3 \\
\hline 1.05365 & 3.95620 & 81.35 & 42.146 & 746.8 \\
\hline \multicolumn{5}{|c|}{ 1.2-Diclorethane-MMA } \\
\hline 3.78930 & 0.96215 & 20.44 & -10.563 & -222.0 \\
\hline 2.19650 & 0.95465 & 30.54 & -8.163 & -258.4 \\
\hline 3.08530 & 1.99605 & 39.56 & -13.193 & -258.8 \\
\hline 2.18360 & 2.19590 & 50.43 & -10.334 & -234.9 \\
\hline 1.86480 & 4.33870 & 70.18 & -8.490 & -135.9 \\
\hline 1.01320 & 4.15480 & 80.58 & -4.322 & -82.9 \\
\hline \multicolumn{5}{|c|}{ Acetic acid-MMA } \\
\hline 1.23510 & 3.01265 & 19.73 & 4.712 & 75.4 \\
\hline 1.47550 & 2.07585 & 29.88 & 5.711 & 115.8 \\
\hline 2.59870 & 1.66495 & 48.34 & 8.852 & 164.9 \\
\hline 4.39920 & 1.77515 & 59.77 & 12.481 & 169.8 \\
\hline 5.37725 & 1.35425 & 70.42 & 11.756 & 154.1 \\
\hline 4.91285 & 0.72155 & 80.33 & 7.216 & 118.1 \\
\hline
\end{tabular}

Table 3

\section{Coefficients of polynomials of concentration dependencies} of enthalpies of mixing at $293 \mathrm{~K}$

\begin{tabular}{|l|c|c|c|c|c|c|}
\hline \multicolumn{1}{|c|}{ System } & $a_{0}$ & $a_{1}$ & $a_{2} \cdot 10^{2}$ & $a_{3} \cdot 10^{4}$ & $a_{4} \cdot 10^{6}$ & $S, \mathrm{~J} / \mathrm{mol}$ \\
\hline Acetonitryle-MMA & -0.17 & 3.3244 & 14.8624 & -29.8854 & 11.7025 & 1,09 \\
\hline Benzene-MMA & 0.18 & 1.9643 & 6.1125 & -14.4213 & 6.34106 & 1,07 \\
\hline Hexane-MMA & 0.09 & 43.427 & -52.3174 & 28.2438 & -19.351 & 3,30 \\
\hline 1,2-Diclorethane-MMA & 0.03 & -16.7587 & 32.1835 & -16.7739 & 1.34708 & 1,27 \\
\hline Acetic acid-MMA & 0.02 & 2.8971 & 7.7028 & -16.65 & 6.04928 & 0,38 \\
\hline
\end{tabular}


Table 4 while the magnitude of molecular refraction RM increases

Properties of solvents and solutions

\begin{tabular}{|l|c|c|c|c|}
\hline \multicolumn{1}{|c|}{ Solvent } & $\alpha \cdot 10^{25}$ & $\mathrm{AN}$ & $\mathrm{RM}$ & $\begin{array}{c}\Delta_{\text {mix }} H_{293}, \\
\mathrm{~J} / \mathrm{mol}\end{array}$ \\
\hline Acetonitryle & 1.9005 & 18.90 & 11.13 & 237.2 \\
\hline Benzene & 0.9088 & 8.20 & 26.19 & 110.6 \\
\hline Hexane & 0.7329 & 0.00 & 29.93 & 1095.6 \\
\hline $\begin{array}{l}1,2- \\
\text { Diclorethane }\end{array}$ & 1.7086 & 16.70 & 21.01 & -234.6 \\
\hline Acetic acid & 1.5364 & 52.90 & 12.99 & 167.1 \\
\hline
\end{tabular}

The magnitudes of enthalpies of mixing of equimolar solutions of the investigated system can be ordered in the following row:

\section{Hexane $>$ Acetonitryle $>$ Acetic acid $>$ \\ $>$ Benzene > 1,2-Diclorethane}

\section{Conclusions}

The sign and magnitude of enthalpies of mixing are determined by the balance of energies of intermolecular interaction in solution and in pure substances. For the investigated systems the enthalpies of mixing takes on negative values for the system of 1,2-Diclorethane-MMA and positive ones for the systems with hexane, acetonitryle, acetic acid, and benzene for all investigated concentrations. The negative value of enthalpies of mixing of methylmethacrylate with 1,2-diclorethane can be due to strong interaction of carbon atom of carboxylic group with the chlorine atoms of 1,2-diclorethane molecule.

In the literature devoted to the research of the properties of solutions [15] it was noted that it is very difficult to find general dependences of the properties of solutions on the properties of solvents, which are very divergent. We also were not able to define general dependence of enthalpies of mixing for the investigated systems on the properties of solvent and parameters of multiparameter equations $[16,17]$. Therefore we divided solvents into two groups - non-polar solvents: hexane, benzene, and 1,2-diclorethane and polar solvents: acetonitryle and acetic acid and analyzed the dependence of enthalpies of mixing of equimolar solutions on acceptor number [18] and molecular refraction.

Acetonitryle and acetic acid have very polar molecules; that is why the value of their enthalpies of mixing falls out of general dependence. Molecules of acetic acid form hydrogen bonds with molecules of methylmethacrylate. The atom of nitrogen of acetonitryle is capable of strong electrostatic interaction with the atom of carbon of carboxylic group of esters.

In the order 1,2-diclorethane, benzene and hexane polarity of solvent and acceptor number AN decreases
(Table 4). For this order of solvents the value of enthalpies of mixing with methylmethacrylate increases. It is possible to draw a conclusion that for these three systems with the decrease of polarity and acceptor number of the solvent the intensity of intermolecular interaction between the molecules of solvent and molecules of methylmethacrylate decreases, which results in the increased thermal effect of the solution formation. For molecular refraction there is a reverse dependence - thermal effect decreases with the increase of intermolecular refraction.

\section{References}

[1] George J., Sastry N. and Prasad D.: Fluid Phase Equilibria, 2003, 214, 39.

[2] Peralta R.: Int. J. Thermophysics, 2003, 24, 1061.

[3] Peralta R.: Thermochimica Acta, 2003, 398, 39.

[4] Peralta R.: J. Chem. Thermodynamics, 2003, 35, 239.

[5] Peralta R.: Phys. \& Chem. of Liquids, 2003, 41, 371.

[6] Peralta R.: J. Solution Chem., 2004, 33, 337.

[7] Wisniak J., Peralta R., Ramiro I. et al.: J. Chem. Thermodynamics, 2005, 37, 729.

[8] Wisniak J., Cortez G., Peralta R. et al.: J. Solution Chem., 2007, 36, 997.

[9] Sastry N.: Int. J. Thermophysics, 1996, 17, 1289.

[10] Sastry N.: Int. J. Thermophysics, 1997, 18, 1387.

[11] Dibrivny V., Van-Chin-Syan Yu. and Melnyk G.: Chem. \& Chem. Techn., 2008, 1, 1.

[12] Belousov V. and Morachevskii A.: Teploty Smesheniya Zhydkostey. Khimiya, Leningrad 1970.

[13] Nikol'skii B. (Ed.): Spravochnik Khimika, V.2. Khimiya, Leningrad 1966.

[14] Knunyants I. (Ed.): Khimicheskiy Entsiklopedicheskiy Slovar. Sov. Entsiklopediya, Moskwa 1983.

[15] Smirnova N.: Molekularnye Teorii Rastvorov. Khimiya, Leningrad 1987.

[16] Yevchuk I., Makitra R., Palchycova O. et al.: Chem. \& Chem. Techn., 2008, 1, 7.

[17] Dimroth K., Reichardt C. and Siepmann T.: Leibigs Annallen der Chemie, 1963, 661, 1.

[18] Mayer U., Gerder W. and Gutman V.: Monatshefte für Chemie, 1977, 108, 1.

\section{ЕНТАЛЬПІї ЗМШШУВАННЯ МЕТИЛМЕТАКРИЛАТУ 3 ДЕЯКИМИ ОРГАНІЧНИМИ РОЗЧИННИКАМИ}

Анотація. Калориметричним методом визначені ентальпії змішування бінарних систем, утворених метилметакрилатом з гексаном, бензеном, ацетонітрилом, 1,2-дихлоретаном і оцтовою кислотою при 293 К та атмосферному тиску. Концентраційні залежності ентальпії змішування апроксимовані степеневими поліномами.

Ключові слова: розчини, калориметрія, ентальпія змімування, метилметакрилат, гексан, бензен, ацетонітрил, 1,2-дихлоретан, оцтова кислота. 